\title{
Editorial 20/2
}

\section{H. Österle • K. Heyden}

Published online: 13 May 2010

(C) Institute of Information Management, University of St. Gallen 2010

Dear readers of Electronic Markets,

Welcome to the second issue of Electronic Markets' twentieth volume! We first present a focus theme section on "Pricing in electronic markets and networks" which comprises five articles and was guest edited by Martin Spann, Andreas Herrmann as well as David Sprott. We are grateful to them for their effort in successfully conceiving this focus theme section and thank all reviewers involved. As usual, the articles of this focus section will be introduced in a separate preface.

In addition to the focus theme articles this issue features two general research contributions. The first was authored by Samuel Otim and Varun Grover and addresses "ECommerce: A Brand Name's Curse". This paper argues that the easy access to Electronic Commerce also reduces the entry barriers for counterfeiters. As this is primarily a danger to established brands, the authors identify some mechanisms that prevent these undesired effects. The second general research contribution cites case studies on the integration of information systems. Authored by Alexander Schmidt, Boris Otto and Hubert Österle, this paper systematically identifies integration challenges from a practitioner's perspective. Based on three case studies integration problems are described and classified to ascertain why integration efforts often fail. The paper also presents a helpful research agenda in this key domain of the information systems discipline.

Finally, we are happy that Electronic Markets was awarded rank " $A$ " in two recent listings. On the one hand this refers to the ranking of the Australian Research Council (ARC) and the Excellence in Research for Australia (ESA) and on the other to the Index of Information System Journals. We are proud of what our authors have achieved and hope that you continue to contribute to Electronic Markets. Of course any feedback to the journal, future focus themes, position papers or general research is highly appreciated.

Best regards,

Your Electronic Markets editorial team

Hubert Österle

Karen Heyden

\footnotetext{
H. Österle $(\bowtie)$

Institute of Information Management, University of St. Gallen, Müller-Friedberg-Strasse 8,

CH-9000 St. Gallen, Switzerland

e-mail: hubert.oesterle@unisg.ch

K. Heyden

Information Systems Institute, University of Leipzig,

Grimmaische Str. 12,

04109 Leipzig, Germany

e-mail: heyden@wifa.uni-leipzig.de
} 